\title{
LXXVIII. An account of a vegetable wax from Brazil
}

\section{William Thomas Brande Esq. F.R.S.}

To cite this article: William Thomas Brande Esq. F.R.S. (1811) LXXVIII. An account of a vegetable wax from Brazil , Philosophical Magazine Series 1, 38:164, 429-434, DOI: 10.1080/14786441108638682

To link to this article: http://dx.doi.org/10.1080/14786441108638682

曲 Published online: 27 Jul 2009.

Submit your article to this journal $\asymp$

Џ Article views: 2

Q View related articles $\sqsubset$ 
Kan-Tah-HaH-Ko-NaH. November: the month when the "vegetation is chiefly fallen down," having been killed by the frost.-Evergreens, of which the number of species in the country of the Six-Nations is very considerable,-such as Pinus, Larix, Abies, Thuja, Cupressus, not to mention the smaller, but yet conspicuous, Taxus, Rhododendron, Kalmia, and many others, -are, doubtless, intended to be excepted from the observation, which is exclusively restricted to deciduous vegetables, and chiefly those of an arborescent stature.

LXXVIII. An Account of a vegetalle Wax from Brazil. By William Thomas Brande, Esq. F.R.S.*

$\S \mathrm{I}$. T $\mathrm{TE}$ vegetable wax described in this paper was given to the president by lord Grenville, with a wish on the part of his lordship that its properties should be investigated, in the hope that it might prove an useful substiute for bees wax, and constitute, in due time, a new article of commerce between the Brazils and this country.

It was transmitted to lord Grenville from Rio de Janeiro, by the comte de Galveas, as a new article lately brought to that city from the northernmost parts of the Brazilian dominions, the capiteneas of Rio Grande and Seara, between the latitudes of three and seven degrees north: it is said to be the production of a tree of slow growth, called by the natives Carnauba, which also produces a gum used as food for men, and another substance employed fur fattening poultry.

When the comte wrote to lord Grenville in July last, orders had been sent to the governors of the districts where it grows, requiring them to report more particularly on the nature and qualities of this interesting tree: we may therefore hope that information will soon be obtained, whether the article can be procured in abundance, and at a reasonable price; in which case it will become a valuable addition

- From the Plilosophical Transactions for 1811, part ii. 
to the comforts of mankind, by reducing the price and improving the quality of candles, flambeaux, \&c.

The article, in the state in which it was sent, resembles much that described by Humboldt as the produce of the Ceroxylon Andicola ; but it is not likely to be the same, as Humboldt's wax is collected from a stately palm-tree, which grows on the high mountains from 900 to 1450 toises above the level of the sea, and on the edge of the regions of perpetual snow. On the other hand, the Brazilian plant is described as a slow-growing tree, but not as a large one, and there are no high mountains delineated in the most accurate and recent maps of the capiteneas where it is found. But a more decisive argument against their identity is the analysis of Vauquelin, published by Humboldt, which shows that the produce of the Ceroxylon cousists of twothirds resin and only one-third wax; but the Brazilian article is entirely wax, and affords not the smallest trace of resin. The Brazilian plant, however, was not entirely unknown to Humboldt; for it appears from his book, that M. Correa had informed him that a palm, called Carnauba by the natives of Brazil, produced wax from its leaves.

\$II.-1. The wax in its rough state is in the form of a coarse pale-gray powder, soft to the touch, and mixed with various impurities, consisting chiefly of fibres of the bark of the tree, which, when separated by a siere, amount to about 40 per ccnt.

It has an agreeable odour, somewhat resembling new hay, but scarcely any taste.

At $206^{\circ}$ Fahrenheit, it enters into perfect fusion, and in this state it may be further purified by passing it through fine linen. By this process it acquires a dirty-green colour, and its peculiar smell becomes more evident. When cold, it is moderately hard and brittle. Its specific gravity is 980 .

2. Water exerts no action on the wax, unless boiled with it for some hours; it then acquires a slight brown tinge, and the peculiar odour of the wax.

3. Alcohol does not dissolve any portion of the wax, unless heat be applied.

Two fluid ounces of boiling alcohol, spec. grav. $\cdot 826$, dis. solve about ten grains of the wax, of wbich cight grains are deposited as the solution cools, and the remaining two grains may be afterwards precipitated by the addition of water, or mav be obtained unaltered by evaporating the alcohol.

The solution of the wax in alcohol has a slightly green tinge.

$$
\text { * Plantes Equinoctiales, p. } 3 .
$$


4. Sulphuric ether, spec. grav. $\cdot 7563$, dissolves a very minute portion of the wax, at the temperature of $60^{\circ}$.

Two fluid ounces of boiling sulphuric ether dissolve thirty grains of the wax, of which twenty-six grains are deposited by cooling the solution, and the remaining four grains may be obtained by allowing the ether to evaporate spontaneously.

5. The fixed oils very readily dissolve the wax at the temperature of boiling water, and form with it compounds of an intermediate consistence, very analogous to those which are obtained with common bees wax.

In examining some combinations which I had made of the vcgetable wax with olive oil, I was surprised to find them perfectly soluble in ether, and sparingly soluble in boiling alcohol.

As it is commonly stated that the fixed oils are insoluble in ether and in alcohol, $I$ was led to attribute the solution of the oil, in these instances, to its being combined with the wax; but subsequent experiments, of which I shall state the general results, have shown me that these opinions are erroneous.

Four fluid ounces of sulphuric ether, spec. grav. 7563 , dissolve a fluid ounce and a quarter of the expressed oil of almonds; of olive oil, the same quantity of the ether dissolves a fluid ounce and a half; of linseed oil, two fluid ounces and a half; and castor oil is soluble in any proportion in sulphuric ether of the above specific gravity.

The expressed oils of almonds and of olives are very sparingly soluble in alcohol, spec. grav. $\cdot 820$.

Linseed oil is more soluble than the two former. Four fluid ounces of alcohol, spec. grav. $\cdot 820$, dissolve nearly one fluid drachm.

Castor oil is perfectly soluble in every proportion in alcohol, spec. grav. 820 . In alcohol of a higher specific gravity, as $\cdot 840$, it is very sparingly soluble *.

As some of the difficultly soluble resins are more easily dissolved in alcohol to which a small proportion of camphor has been added, I endeavoured to ascertain whether the fixed oils were rendered more soluble by the same means, but found that this was not the case, excepting with regard to castor oil, which, although very sparingly dissolved by alcohol of a spec. grav. above $840^{\circ}$, becomes abundantly

* The solubility of castor oil in alcohol was mentioned to me some months ago by $\mathrm{Dr}$. Wollaston, who also informed me, that it had on that account been employed to adulterate certain essential oils of high value, especially the oil of cloves. 


\section{An Account of a vegetalle Wax from Brazil.}

soluble by the addition of one part of camphor to eight parts of the alcohol.

Boiling alcohol, spec. grav. $\cdot 840$, takes up a considerable portion of castur oil and of linseed oil; it also dissolves a small quantity of the oils of almonds and of olives; but they are copiously deposited during the cooling of the alcohol, and only a small portion retained in permanent solution.

When water is added to any of these solutions of the fixed oils in ether, and in alcohol, a milky mixture is formed, and the oil gradually separates upon the surface, without having undergone any apparent alteration.

6. One hundred grains of the wax were boiled for half an hour in a solution of caustic potash, spec. grav. 1090. The solution acquired a pale-rose colour, but appeared to exert no further action on the wax, which after having been washed with warm water retained its fusibility and other properties. No combination therefore, similar to a soap, was produced, nor was any precipitate occasioned by the addition of acids to the rose-coloured alkaline solution.

7. The effects produced by boiling the wax in solutions of pure soda, and of the subcarbonates of soda and of potash, were analogous to those of the caustic potash.

8. Solutions of pure and of carbonated ammonia exert scarcely any action on the wax.

9. When the wax is boiled in nitric acid, spec. grav. $1 \cdot 45$, there is some escape of nitrous gas, and the colour of the wax is gradually changed to a deep yellow.

When the wax is removed from the acid, and washed with hot water, it is found to have become more brittle and hard, but it still retains much of its peculiar odour.

In this state it remains insoluble in the alkalits; but they now change its colour to a very bright brown, which is destroyed by washing with dilute muriatic acid, and its original yellow colour restored.

Neither the fusibility nor the inflammability of the wax is impaired by this process.

Nitric acid, diluted with eight parts of water, produces the same change in the colour of the wax as the concentrated acid.

Having been uneuccessful in my attempts to blcach the wax in its original state, I made some experiments to ascertain whether its colour could be more easily destroyed, after it had been acted upon by nitric acid, and found that, by exposing it spread upon glass to the action of light, it became in the course of three weeks of a pale-straw colour, 
and on the surface nearly white. The same change was produced by steeping the wax in thin plates in an aqueous solution of oxymuriatic gas, but I have not hitherto succeeded in rendering it perfectly white.

10. Muriatic acid has little action on the wax: when boiled upon it for some hours, it destroys much of its colour.

11. Sulphuric acid changes the colour of the wax to a pale brown, and when water is added, it becomes of a deep rose colour; the inflammability and the fusibility of the wax are slightly impaired ty this process.

When heat is applied; the wax is decomposed with the usual phænomena, sulphurous acid is developed, and charcoal deposited.

12. Acetic acid has very little action on the wax, when cold.

When the wax is boiled in this acid, a minute portion is dissolved, and again deposited as the solution cools. By long continued boiling in acetic acid, the wax is rendered nearly white; but when it is afterwards washed with water, and fused, it resumes its former colour.

13. When the wax is fused in oxymuriatic gas, it is ra. pidly decomposed, and parting with hydrogen and oxygen, muriatic acid and water are formed; and charcoal is deposited.

14. The results of the destructive distillation of the vegetable wax are very analogous to those of bees wax.

An acid liquor mixed with a volatile oil are the first products; these are succeeded by a large proportion of a butyraceous oil, and a very small quantity of charcoal affording traces of lime remains in the retort. During the process, a little carburetted hydrogen gas is given off.

I have not considered it necessary to dwell upon the relative proportions of these different products, as they wilt necessarily vary according to the rapidity with which the distillation is conducted.

$\S I I I$.-From the preceding detail of experiments it appears, that although the South American vegetable wax possesses the characteristic properties of bees wax, it differs from that substance in many of its chemical habitudes; it also differs from the other varieties of wax, namely, the wax of the Myrica cerifera*, of lac $\uparrow$, and of white lac $\ddagger$.

* Vide Dr. Bostock's Experiments on the Wax of the Myrica cerifera, in Nicholson's Journa for March 1803.

$\uparrow$ Vide Analytical Experiments and Observations on Lac, by Charles Hatchett, Esq. F.R.S. in the Fhilosophical Transactions for 1804.

$\ddagger$ Vide Observations and Experiments on a Wax-like Substance from Madras, by George Pearson, M.D. F, R.S. in the Phil. Trans, for 1794 .

Vol. 38. No. 164. Dec. 1811 .

E

The 
The attempts which $I$ have made to bleach the wax have been conducted on a small scale; but from the experiments related it appears that, after the colour has been changed by the action of very dilute nitric acid, it may be rendered nearly white by the usual means. I have not had sufficient time to ascertain whether the wax can be more effectually bleached by long continued exposure, nor have I had an opportunity of submitting it to the processes employed by the bleachers of bees wax.

Perhaps the most important part of the present inquiry is that which relates to the combustion of the vegetable wax in the form of candles.

The trials which have been made to ascertain its fitness for this purpose are extremely satisfactory; and when the wick is properly proportioned to the size of the eandle, the combustion is as perfect and uniform as that of commor bees wax.

The addition of from one-eighth to one-tenth part of tallow is sufficient to obviate the brittleness of the wax in its pure state, without giving it any unpleasant smell, or materially impairing the brilliancy of its flame. A mixture of three parts of the vegetable wax with one part of bees wax also makes very excellent candles.

LXXIX. Theorems for calculating the Temperaments of such regular Douzeaves as are commensurable, or defined by a certain Number of equal Parts, into which the Octave is divided. By John Farey, Sen.

\section{To Mr. Tilloch.}

Sir, $\mathrm{H}_{\text {aving been applied to by a musical friend, to point }}$ out the method of calculating the Temperament of the Fifths, in any given commensurable system of Musical Intervals, without reference to the Memoirs of the Academy of Sciences (a work which many have not the opportunity of consulting) as is done in the 1st, and several others of the Scholia to my Six Musical Theorems in your 36 th volume, p.45; I beg the favour of you to give a place to the following Observations and Theorems on Commensurable Systems.

It is well known, that merely giving the number of equal parts into which the octave is to be divided, is not sufficient to define, in all cases, the regular douzeave that re sults, or system wherein all the Fifths to a given extent are alike tempered; the common property of which is, as Dr. 